\title{
Development of Educational Content for Nurses to Prevent Safety Accidents of Hospitalized Children: Delphi Approach
}

\author{
Yun Sil Lee ${ }^{1}$, Won-Oak $\mathrm{Oh}^{2}$ \\ ${ }^{1}$ Staff Nurse, Anam Hospital, Korea University · Graduate Student, Graduate School, College of Nursing, Korea University, Seoul; ${ }^{2}$ Professor, College of Nursing, \\ Korea University, Seoul, Korea
}

Purpose: The purpose of this study was to develop content for safety education to prevent hospital safety accidents among hospitalized children and to investigate the status of safety education performed by nurses. Methods: First, the Delphi method was used, with 18 experts, to develop educational contents for preventing safety accidents. Second, an exploratory survey was performed of the actual status of safety education for preventing safety accidents among hospitalized children using a questionnaire developed based on the Delphi method. The participants of this study were 159 nurses with at least 6 months of work experience. Results: The educational content developed through the Delphi method for preventing safety accidents among hospitalized children contained seven domains (falls, injury, electric shocks/burns, suffocation/aspiration, poisoning/abuse, kidnapping, medical devices) with 44 topics. The item mean of nurses'perceptions of the importance of child safety education was 4.18 , and the actual performance score was 3.72, which was a statistically significant difference ( $t=11.58, p<.001)$. Conclusion: These seven comprehensive domains of accident prevention education for hospitalized children are expected to be useful for interventions to support the safety of hospitalized children.

Key words: Child, hospitalized; Safety; Accidents; Delphi technique

\section{Corresponding author Won-Oak Oh}

https://orcid.org/0000-0003-0156-3422

College of Nursing, Korea University,

145 Anam-ro, Seongbuk-gu, Seoul 02841, Korea

TEL +82-2-3290-4928 FAX +82-2-928-9108

E-MAIL wooh@korea.ac.kr

*This article was adapted from a thesis by Yun Sil Lee in partial fulfillment of the requirements for the master's degree at Korea University of Korea. *This study was supported by a harmony scholarship from the Seoul Nurses Association in 2016.

Received Dec 11, 2018 Revised Dec 22, 2018 Accepted Dec 23, 2018 (a) This is an Open Access article distributed under the terms of the Creative Commons Attribution NonCommercial License (http://creativecommons.org/licenses/by-nc/4.0/) which permits unrestricted noncommercial use, distribution, and reproduction in any medium, provided the original work is properly cited.

\section{INTRODUCTION}

In 2016, the death rate of South Korean children aged 1 to 14 years was 2.8 per 100,000 children [1]. The proportion of safety accidents among children under 14 years of age was $32.7 \%$ in 2016 and $36.2 \%$ in 2017, showing a steady increase [2]. Child safety accidents accounted for $28.3 \%$ of the total safety accidents in the United States of America in 2015 and 12.4\% in Australia indicating that Korea has a significantly higher incidence of safety accidents than other advanced countries $[3,4]$.

In young children, $74.3 \%$ of these accidents occurred in indoor environments such as homes, playgrounds, and educational facilities [2]. Child safety accidents in medical facilities such as hospitals, where caregivers are present and observant, accounted for a relatively small proportion of the total $(0.7 \%)$. However, safety accidents in hospitals are mostly predictable events that can be prevented through active education and monitoring [5]. Therefore, focusing on safety accidents among hospitalized children is important.

Parents expect their children to be treated in a safe environment when they are hospitalized for an illness. Children who are hospitalized, like other patients, have the right to receive safe, high-quality medical care, which requires the clinical 
workforce to be extremely diligent [6]. "Patient safety" refers to protection of a person receiving treatment from any further risk or accident, and involves reducing the risk of unnecessary harm associated with health care to an acceptable minimum [7]. For children, the unfamiliar surroundings of the hospital and the use of unfamiliar medical devices for treatment increase the incidence of safety accidents, with reduced physical function due to the illness posing an additional danger. Despite the high likelihood of safety accidents involving inpatients owing to their physical/psychological characteristics and environmental influences, most studies have been limited to falls $[8,9]$.

Domestic studies related to falls among hospitalized children have included research on the effectiveness of fall prevention education for caregivers [8] and the development of fall risk prediction tools for hospitalized children [9]. No study has yet investigated all types of safety accidents among hospitalized children in Korea, and even studies involving falls among hospitalized children are in the early stages.

Outside of Korea, Cooper and Nolt [10] developed fall risk assessment tools and fall prevention programs for hospitalized children, and Razmus et al.[11] developed a tool known as CHAMPS, which includes an assessment of fall risk factors and interventions for hospitalized children. Moreover, a variety of fall risk assessment tools, such as the I'm Safe tool [12] and the Humpy Dumpty Falls Scale [13], have been developed to provide fall risk prevention education appropriate for each level according to the actual clinical fall risk score. The Safety in the Seconds Program [14] was developed to prevent not only falls, but also safety accidents more broadly, among hospitalized children. Parents of children admitted to pediatric emergency rooms were also included in this study, and the effectiveness of the program was confirmed [14]. Thus, in other countries, various fall assessment tools have been developed and standardized preventive education interventions are attempted according to the risk level.

However, very few studies in Korea have investigated strategies to prevent safety accidents among hospitalized children. Considering that the safety system of the hospitals in a given country is very important for patients' safety [15], it is necessary to develop educational content for safety accident prevention that would be applicable in the hospital environment of Korea. The development of assessment tools for the safety of hospitalized children has focused only on falls [8,9, $16]$, and no interventions have been conducted to comprehensively prevent safety accidents among hospitalized children and caregivers. In addition, there is no information on the types of safety accidents to which hospitalized children are exposed, and no details are available on the actual contents of safety education and concrete implementation meth- ods for the prevention of child safety accidents, although such information is a prerequisite for further studies.

Therefore, through the Delphi method involving expert groups, this study was designed to develop educational contents to prevent safety accidents among hospitalized children according to their risk factors, based on a consideration of the characteristics of inpatients, facilities, and the environment. Moreover, by investigating the actual status of safety education for accident prevention among hospitalized children, it was expected that clinical nurses could provide basic data to support the further development of education and nursing strategies.

\section{METHODS}

\section{Safety Education Content Development Process Using the Delphi Method}

The Delphi method was used to develop educational content for preventing safety accidents among hospitalized children. This process involved reaching collective agreement over three rounds of discussions among the same group of 18 experts. The expert panelists confirmed to the selection criteria, were clear about the purpose and procedures of the study, and voluntarily agreed to take part.

The Delphi experts were required to be one of the following occupational categories: pediatric nursing professors, pediatric unit managers, general pediatric ward nurses, pediatric intravenous specialist nurses, nurse practitioners, or pediatricians, all of whom provide direct treatment and nursing care to children or have a professional knowledge of pediatric care at general hospitals. The Delphi method for the development of educational content for the prevention of safety accidents among hospitalized children was conducted in three rounds from June 2016 to August 2016.

\section{1) The first round}

The first Delphi panel was conducted to elicit the main content of education for the safety of children in hospitals. For this purpose, seven major open questions were derived through a literature review. The seven open questions were related to the major safety accidents experienced by hospitalized children and consisted of types of safety accidents, locations of major safety accidents in the hospital, how to prevent safety accidents according to developmental stages, major educational subjects, effective education methods, and other opinions. The data were analyzed using content analysis, a qualitative research methods. This method of analysis is necessary to derive repeatable and reasonable inferences from research data [17]. In other words, the collected complex data consisted 
of meaningful subjects or categories related to educational content for preventing accidents among hospitalized children. At this stage, a total of 116 meaningful statements were derived, of which 80 were related to educational content for preventing safety accidents, 23 were related to the educational method, seven were related to the timing of education, and seven were related to the major educational subjects. In particular, the educational content for preventing safety accidents was divided into seven domains; falls, injury, electric shocks/ burns, suffocation/aspiration, poisoning/abuse, kidnapping, and medical devices.

\section{2) The second round}

The second Delphi survey was aimed at collecting expert opinions on the results of the first Delphi survey and eliciting further comments. The researchers reflected on the opinions of Delphi experts on the suitability of safety education for hospitalized children in relation to the seven areas and the educational intervention derived by analyzing the results of the first Delphi survey. A 5-point Likert scale was used to determine the validity of the criteria in the second Delphi survey. In addition, 2 themes were used to narrow down the priority of safety accident prevention education: the places where safety accidents were most likely to occur and the stages of child development. For the other factors, further comments were made.

The results of the second Delphi survey were derived from the content validity index (CVI), using a cut-off value point 0.7. Some topics considered significant based on the previous literature or expert opinion were also included. Through this process, educational domains with sub-topics, the educational method, the timing of education, and the major subjects for preventing safety accidents among hospitalized children were re-determined.

\section{3) The third round}

The third Delphi survey required the same group of experts to review the detailed topics drawn from the second Delphi survey, so that proposals or modifications related to each topic could be presented in the revised opening columns.

\section{Survey on Nurses' Preventive Education on Child Safety Accidents}

\section{1) Research design}

This was an exploratory survey study to investigate the actual status of the safety education for hospitalized children received by nurses.

\section{2) Participants}

The participants of this survey were nurses working at two university hospitals located in Seoul and one in the city of Ansan, who understood the purpose of the study and expressed their willingness to participate. Data were collected at the level of the university hospital because hospitals implement a safety accident prevention strategy for hospitalized children as part of the evaluation of their medical institution certification. The three hospitals chosen for this study were considered to be suitable for data collection because they are university hospitals that have continuously passed the medical institution certification. The specific selection criterion for nurses was 6 months or more of work experience in pediatric inpatient department. The exclusion criterion was not having recently experienced pediatric care for more than 3 years. The questionnaire survey was conducted among a total of 180 nurses (60 nurses each from the three university hospitals). All 180 questionnaires were collected; the return rate was $100 \%$. After excluding 21 questionnaires owing to significant missing data, 159 questionnaires were used for the analysis.

\section{3) Measurements}

(1) The importance of safety education for the prevention of hospital safety accidents and performance assessment tool

(2) A 5-point Likert scale was developed to measure nurses' perceptions of the importance and performances of safety education for the prevention of hospital safety accidents based on the Delphi results. The items of safety education for the prevention of safety accidents among hospitalized children were classified into seven domains (falls, injuries, electric shocks/burns, suffocation/aspiration, poisoning/abuse, kidnapping, and medical devices) with 33 items. Additionally, nine items related to safety education methods, six items related to the duration of accident prevention education, and an additional 27 items related to management strategies besides the existing safety precautions involved in direct nursing activity were measured. The reliability of internal consistency among the items in the questionnaire in terms of the Cronbach's $\alpha$ was 96 for perceptions of the importance of educational content for safety accident prevention, .95 for the actual status of safety education, .83 for the safety education method, .71 for the duration of safety prevention education, and .95 for additional management strategies besides existing safety precautions involved in direct nursing activity.

(3) Furthermore, since children may have different types of safety accidents depending on their developmental stage, nurses were asked to assess the priority of the educational domains of safety accident prevention according 
to children's developmental stages.

(4) General characteristics

(5) The general characteristics examined included age, sex, marital status, educational level, total clinical experience, current work ward, current workplace experience, job position, safety education, and number of safety education sessions conducted.

\section{4) Data collection methods and ethical considerations}

This study was conducted from September 13 to September 26, 2016. The study was approved by the Research Ethics Committee of K University (IRB approval number: 1040548KU-IRB-16-41-A-2). For data collection, the purpose, contents, and procedure of the study were introduced to the nursing department and nurses at the university's affiliated hospitals. The questionnaire was distributed to nurses who voluntarily agreed to participate in the study after the researchers explained the purpose, content, and methods of the study to them. The participants responded to the questionnaire after voluntarily signing the consent form. Those who participated in the study were offered small incentives.

\section{5) Data analysis}

Descriptive statistics were calculated for demographic variables and the nurses' perceptions of the importance of hospitalized children's safety education and the actual status thereof. Differences in the nurses' perceptions of the importance and actual status of hospitalized children's safety education according to demographic factors were analyzed using the t-test, analysis of variance and the Duncan multiple comparison test. A Comparative analysis of nurses' perceptions of the importance and actual status of hospitalized children's safety education was performed using the t-test. All data analyses were performed using SAS (version 9.4; SAS Institute, Cary, NC, USA).

\section{RESULTS}

\section{Results of Safety Education Content for Preventing Safety Accidents among Hospitalized Children}

The results of the first, second, and third rounds of the Delphi method are summarized as follows. Seven distinct themes, with 44 sub-topics, were identified among the educational content for preventing safety accidents among hospitalized children (falls, injury, electric shocks/burns, suffocation/aspiration, poisoning/abuse, kidnapping, and medical devices) (Table 1).

The sub-topics were as follows: nine related to preventive education methods for the prevention of safety accidents among hospitalized children, six related to the timing of preventive education, and three related to preventive education subjects. Additional management strategies to be implemented in addition to direct education for the prevention of accidents among hospitalized children were confirmed in two domains with 22 detailed topics (Table 2).

\section{Actual Status of Safety Education for Hospitalized Children}

\section{1) General characteristics of the nurses}

All 159 participants were women. Among the participants, there were $31.45 \%$ (50 participants) under the age of $25,42.77 \%$ (68 participants) from 26 to 30 years old, 21.38\%(34 participants) from 31 to 35 years old, 3.14\% (5 participants) from 36 to 40 years old, and $1.26 \%$ (2 participants) over 41 years old. The vast majority of the participants $(80.50 \% ; 128$ participants) were single, while $19.50 \%$ (31 participants) were married. Regarding total clinical experience, 6.92\% (11 participants) had worked for less than 1 year, $49.69 \%$ (79 participants) for 1 to less than 5 years, 33.33\% (53 participants) for 5 to less than 10 years, and $10.06 \%$ (16 participants) for more than 10 years. Regarding job position, $47.17 \%$ (75 participants) were general nurses and $52.83 \%$ (84 participants) were charge or head nurses.

A minority of participants $(33.33 \%$; 53 participants) reported that they had performed children's safety education, while $66.67 \%$ (106 participants) did not. Among those who responded that they had performed child safety education, $45.28 \%$ (24 participants) answered that they had done so once or twice, $41.51 \%$ (22 participants) that they had done so three to five times, and $13.21 \%$ (7 participants) that they had done so more than 6 times.

\section{2) Nurses' perceptions of the importance of safety education for hospitalized children and actual status}

Nurses' perceptions of the importance of safety education for hospitalized children were evaluated on a 5-point scale; the total score was $4.18 \pm 0.51$. Domain 1 (falls) showed the highest score $(4.27 \pm 0.49)$, while domain 5 (poisoning/abuse) showed the lowest (3.98 \pm 0.82 ) (Table 3).

Significant differences in perceptions of the importance of hospitalized children's safety education were found according to age $(\mathrm{F}=3.76, p=.006)$, total clinical experience $(\mathrm{F}=3.47, p=$ $.018)$, marital status $(\mathrm{t}=-1.99, p=.049)$, and job position $(\mathrm{t}=-2.31$, $p=.022$ ). According to the Duncan test, nurses over 42 years old $(4.58 \pm 0.43)$ were more aware of the importance of child safety education than were younger nurses (3.98 \pm 0.49$)$. Awareness was higher among married participants $(4.35 \pm 0.44)$ than among single participants $(4.14 \pm 0.52)$. Longer total clinical experience 
Table 1. Final Content for Safety Education for the Prevention of Safety Accidents of Hospitalized Children

\begin{tabular}{|c|c|}
\hline Domains & Detailed topics \\
\hline $\begin{array}{l}\text { Domain } 1 \\
\text { Falls (8 items) }\end{array}$ & $\begin{array}{l}\text { - Preventing leaning or touching windows, curtains etc. } \\
\text { - Preventing standing on the window rail, air-conditioner, sink, and toilet. } \\
\text { - How to use the patient bed and bedside rail. } \\
\text { - Raising the patient's bedside rail and lock the bed wheels. } \\
\text { - Preventing running in bed. } \\
\text { - Wearing a seatbelt when using a stroller and wheelchair. } \\
\text { - Using a patient-fitting stroller and wheelchair. } \\
\text { - Preventing children from getting caught between the mattress and the side rail. }\end{array}$ \\
\hline $\begin{array}{l}\text { Domain } 2 \\
\text { Injury (12 items) }\end{array}$ & $\begin{array}{l}\text { - Preventing using a mobile phone while walking. } \\
\text { - Preventing walking barefoot in hallways and wards. } \\
\text { - Preventing standing on IV poles. } \\
\text { - Preventing running in hospital corridors, wards, shower booth, and bathroom. } \\
\text { - Managing areas of wetness in the hospital corridors, wards, shower booth, and bathroom floor. } \\
\text { - Management of lines, such as electric wires that can be caught on the foot. } \\
\text { - Removing dangerous things next to the patient's bed. } \\
\text { - Caution with an IV pole or wheelchair when entering an elevator. } \\
\text { - Safety education for the opening and closing of elevators and the room door. } \\
\text { - Managing IV fluids and IV fluid infusion line. } \\
\text { - Precautions when using an IV pole, wheelchair, and stroller. } \\
\text { - Caring point for use of IV pole and wheelchair with infusion pump or syringe pump attached. }\end{array}$ \\
\hline $\begin{array}{l}\text { Domain } 3 \\
\text { Electric shocks/burns (11 items) }\end{array}$ & $\begin{array}{l}\text { - Prohibiting using electric heating devices in the hospital. } \\
\text { - Ensuring electrical outlet safety plug is installed. } \\
\text { - Preventing touching electrical outlets and wires that are peeled off with a wet hand. } \\
\text { - Removing plugs of unused electrical appliances from the outlet. } \\
\text { - Preventing putting things like chopsticks in an electrical outlet. } \\
\text { - Preventing children from touching hot plates. } \\
\text { - Caution when using hot water or heat packs. } \\
\text { - Precautions when using water heaters. } \\
\text { - Familiarization with emergency exits and countermeasures in case of a fire in the hospital. } \\
\text { - Precautions when using hot water from the sink. } \\
\text { - How to use a fire hydrant. }\end{array}$ \\
\hline $\begin{array}{l}\text { Domain } 4 \\
\text { Suffocation/aspiration (4 items) }\end{array}$ & $\begin{array}{l}\text { - Preventing the consumption of any food that can lead to suffocation. } \\
\text { - Management of lines, such as IV fluid lines, which can be wound around the patient's neck. } \\
\text { - Training to burp after milking. } \\
\text { - Preventing using toys which can be taken apart into small pieces. }\end{array}$ \\
\hline $\begin{array}{l}\text { Domain } 5 \\
\text { Poisoning/abuse (2 items) }\end{array}$ & $\begin{array}{l}\cdot \text { How to manage medicine and chemicals. } \\
\cdot \text { How to use hand sanitizer or liquid soap installed in the ward. }\end{array}$ \\
\hline $\begin{array}{l}\text { Domain } 6 \\
\text { Kidnapping (5 items) }\end{array}$ & $\begin{array}{l}\text { - Keeping the child from moving around alone in the hospital. } \\
\cdot \text { Wearing patient uniforms at all times. } \\
\cdot \text { Wearing patient bracelet at all times. } \\
\text { - Training child not to follow strangers. } \\
\text { - How to report strangers. }\end{array}$ \\
\hline $\begin{array}{l}\text { Domain } 7 \\
\text { Medical devices ( } 2 \text { items) }\end{array}$ & $\begin{array}{l}\text { - Precautions when using medical equipment. } \\
\cdot \text { How to use medical devices directly operated by caregivers (parent or facility caring staff). }\end{array}$ \\
\hline
\end{tabular}

IV=Intravenous.

(4.26 \pm 0.40$)$ was associated with higher the perceptions of importance. In addition, charge or head nurses (4.27 \pm 0.49$)$ had higher perceptions of the importance of child safety education than did general staff nurses $(4.08 \pm 0.52)$.

The actual status of safety education for hospitalized chil- dren was evaluated on a 5-point scale, with a total score of $3.72 \pm 0.58$. In terms of sub-area. Domain 7 (medical devices) scored highest $(4.02 \pm 0.80)$, and domain 3 (electric shocks/ burns) scored the lowest (3.40 \pm 0.77 ) (Table 3).

Significant differences in having performed child safety ed- 
Table 2. Inpatient Child Safety Accident Prevention Education Methods, Timing of Education, Targeted Subjects, and Additional Management Strategies

Items

Preventive education methods

Preventive education timing

Preventive education subjects

Additional

Educational

management

strategies
Final results of Delphi survey

1:1 oral education, pamphlets, video, broadcasting, photo books, announcement board (bulletin), mobile application, situation plays and demonstrations, group presentation and discussion.

At the time of hospitalization, continuous education by written distribution of cautions or video, whenever the caregiver changes, additional training in the middle of a long-term hospitalization, repetitive training in each nursing round, training by the responsible nurse once a day.

Guardian, facility caring staff, communicable child.

- Checklist for education evaluation.

- Renewal and systematization of educational manuals.

- Checking the knowledge contained in the new nurse manual.

- Producing easy and fun teaching materials which can be used at any time.

- Periodically showing videos of safety accident prevention.

- Continuous training for nurses (increase in skill).

- Detailed education for managing IV fluids and IV fluid lines.

Development and application of a consent form for compliance with safety rules when preparing admission by the administrative department.

- Development and application of countermeasures in the event of a safety accident.

- Development and application of a concise report preparation form in case of an accident.

- Development and application of education data to prevent safety accidents in the specific developmental stages of children.

Environmental $\quad \cdot$ Making safety caps of hand sanitizer that prevent children from pumping them easily.

management

- Installation of a door safety bar that prevents people from getting caught between doors.

- Confirm whether stroller, wheelchairs, or their seatbelts are broken.

- Replacement of old equipment.

- Removing water from the floor of wards, corridors, and bathrooms.

- Thorough collection of dangerous equipment such as needles and syringes.

- Marking areas expected to pose accident risks with stickers and photos.

- Delineating safety and hazard areas by using color stickers, etc.

- Placing a non-slip pad on the floor of the pediatric ward.

- Relocation of the bed and furniture considering the movement of children and caregivers.

IV=Intravenous.

ucation were found according to age $(\mathrm{F}=4.43, p=.002)$ and marital status ( $\mathrm{t}=2.00, p=.047$ ). According to the Duncan test, nurses from 26 to 30 years old $(3.85 \pm 0.58)$ and those 41 and above $(4.33 \pm 0.21)$ were more likely to have performed child safety education than nurses under 25 years old $(3.53 \pm 0.46)$ and those between 36 and $40(3.13 \pm 0.60)$. Married nurses $(3.91 \pm 0.68)$ had performed more safety education than unmarried nurses $(3.67 \pm 0.55)$.
3) Comparative analysis of nurses' perceptions of the importance and actual status of safety education for hospitalized children

Nurses' responses regarding the importance of each item were compared to the performance score the corresponding item; in all cases, except for two items in domain 1 (falls) and item 29 in domain 6 (kidnapping), the actual performance status was lower than the perceptions of importance $(t=11.58$, $p<.001$ ) (Table 3). 
Table 3. Comparative Analysis of Nurses' Perception of the Importance of Hospitalized Children's Safety Education

$(N=159)$

\begin{tabular}{|c|c|c|c|c|c|c|}
\hline \multirow{2}{*}{ Domains } & \multirow{2}{*}{ Items } & PI & Actual status & Difference & \multirow{2}{*}{$t$} & \multirow{2}{*}{$p$} \\
\hline & & $\mathrm{M} \pm \mathrm{SD}$ & $\mathrm{M} \pm \mathrm{SD}$ & $\mathrm{M} \pm \mathrm{SD}$ & & \\
\hline \multirow{8}{*}{$\begin{array}{l}\text { Falls } \\
\text { (domain 1) }\end{array}$} & 1. Preventing leaning or touching windows, curtains etc. & $3.89 \pm 0.80$ & $3.35 \pm 1.00$ & $0.55 \pm 0.97$ & 7.10 & $<.001$ \\
\hline & $\begin{array}{l}\text { 2. Preventing standing on the window rail, air-conditioner, } \\
\text { sink, and toilet. }\end{array}$ & $4.21 \pm 0.70$ & $3.57 \pm 0.94$ & $0.64 \pm 1.07$ & 7.57 & $<.001$ \\
\hline & 3. How to use the patient bed and bedside rail. & $4.45 \pm 0.62$ & $4.49 \pm 0.65$ & $-0.04 \pm 0.67$ & 0.71 & .481 \\
\hline & 4. Raising the patient's bedside rail and lock the bed wheels. & $4.45 \pm 0.64$ & $4.39 \pm 0.67$ & $0.05 \pm 0.71$ & 0.89 & .372 \\
\hline & 5. Preventing running in bed. & $4.48 \pm 0.63$ & $4.04 \pm 0.92$ & $0.44 \pm 0.92$ & 6.05 & $<.001$ \\
\hline & 6. Wearing a seatbelt when a stroller and wheelchair. & $4.23 \pm 0.71$ & $3.83 \pm 0.92$ & $0.40 \pm 0.85$ & 5.88 & $<.001$ \\
\hline & $\begin{array}{l}\text { 7. Preventing children from getting caught between the } \\
\text { mattress and the side rail. }\end{array}$ & $4.18 \pm 0.71$ & $3.52 \pm 1.01$ & $0.65 \pm 1.01$ & 8.20 & $<.001$ \\
\hline & Sub-total & $4.27 \pm 0.49$ & $3.88 \pm 0.60$ & $0.39 \pm 0.56$ & 8.65 & $<.001$ \\
\hline \multirow{10}{*}{$\begin{array}{l}\text { Injury } \\
\text { (domain 2) }\end{array}$} & 8. Preventing walking barefoot in hallways and wards. & $4.08 \pm 0.76$ & $3.58 \pm 1.01$ & $0.50 \pm 1.02$ & 6.23 & $<.001$ \\
\hline & 9. Preventing standing on IV poles. & $4.45 \pm 0.67$ & $4.14 \pm 0.78$ & $0.30 \pm 0.77$ & 4.95 & $<.001$ \\
\hline & $\begin{array}{l}\text { 10. Preventing running in hospital corridors, wards, shower } \\
\text { booth, and bathroom. }\end{array}$ & $4.42 \pm 0.66$ & $4.08 \pm 0.76$ & $0.35 \pm 0.73$ & 5.98 & $<.001$ \\
\hline & $\begin{array}{l}\text { 11. Managing areas of wetness in the hospital corridors, wards, } \\
\text { shower booth, and bathroom floor. }\end{array}$ & $4.30 \pm 0.70$ & $3.63 \pm 0.91$ & $0.67 \pm 0.85$ & 9.84 & $<.001$ \\
\hline & 12. Removing dangerous things next to the patient's bed. & $4.11 \pm 0.75$ & $3.64 \pm 0.87$ & $0.47 \pm 0.84$ & 7.08 & $<.001$ \\
\hline & $\begin{array}{l}\text { 13. Caution with an IV pole or wheelchair when entering an } \\
\text { elevator. }\end{array}$ & $3.97 \pm 0.81$ & $3.32 \pm 0.95$ & $0.65 \pm 1.03$ & 7.92 & $<.001$ \\
\hline & $\begin{array}{l}\text { 14. Safety education for the opening and closing of elevators } \\
\text { and the room door. }\end{array}$ & $3.86 \pm 0.78$ & $3.17 \pm 0.93$ & $0.69 \pm 1.04$ & 8.36 & $<.001$ \\
\hline & 15. Managing IV fluids and IV fluid infusion line. & $4.30 \pm 0.73$ & $4.05 \pm 0.88$ & $0.25 \pm 0.76$ & 4.07 & $<.001$ \\
\hline & $\begin{array}{l}\text { 16. Caring point for use of IV pole and wheelchair with } \\
\text { infusion pump or syringe pump attached. }\end{array}$ & $4.24 \pm 0.70$ & $4.04 \pm 0.81$ & $0.20 \pm 0.85$ & 2.99 & .003 \\
\hline & Sub-total & $4.19 \pm 0.54$ & $3.74 \pm 0.63$ & $0.45 \pm 0.59$ & 9.67 & $<.001$ \\
\hline \multirow{8}{*}{$\begin{array}{l}\text { Electric shock } \\
\text { /burns } \\
\text { (domain 3) }\end{array}$} & 17. Prohibiting using electric heating devices in the hospital. & $4.01 \pm 0.74$ & $3.54 \pm 0.89$ & $0.47 \pm 0.94$ & 6.24 & $<.001$ \\
\hline & $\begin{array}{l}\text { 18. Preventing touching electrical outlets and wires that are } \\
\text { peeled off with a wet hand. }\end{array}$ & $4.11 \pm 0.85$ & $3.30 \pm 1.00$ & $0.82 \pm 0.91$ & 11.29 & $<.001$ \\
\hline & $\begin{array}{l}\text { 19. Removing plugs of unused electrical appliances from the } \\
\text { outlet. }\end{array}$ & $3.89 \pm 0.89$ & $3.20 \pm 1.04$ & $0.69 \pm 0.96$ & 9.05 & $<.001$ \\
\hline & $\begin{array}{l}\text { 20. Preventing putting things like chopsticks in an electrical } \\
\text { outlet. }\end{array}$ & $4.20 \pm 0.81$ & $3.26 \pm 1.07$ & $0.94 \pm 1.00$ & 11.88 & $<.001$ \\
\hline & 21. Preventing children from touching hot plates. & $4.17 \pm 0.81$ & $3.24 \pm 0.98$ & $0.93 \pm 1.01$ & 11.65 & $<.001$ \\
\hline & 22. Caution when using hot water or heat packs. & $4.31 \pm 0.76$ & $3.84 \pm 0.88$ & $0.47 \pm 0.85$ & 7.01 & $<.001$ \\
\hline & $\begin{array}{l}\text { 23. Familiarization with emergency exits and countermeasures } \\
\text { in case of a fire in the hospital. }\end{array}$ & $4.13 \pm 0.78$ & $3.42 \pm 1.01$ & $0.72 \pm 1.05$ & 8.61 & $<.001$ \\
\hline & Sub-total & $4.12 \pm 0.67$ & $3.40 \pm 0.77$ & $0.72 \pm 0.69$ & 13.11 & $<.001$ \\
\hline \multirow{3}{*}{$\begin{array}{l}\text { Suffocation } \\
\text { /aspiration } \\
\text { (domain 4) }\end{array}$} & $\begin{array}{l}\text { 24. Management of lines, such as IV fluid lines, which can be } \\
\text { wound around the patient's neck. }\end{array}$ & $4.23 \pm 0.71$ & $3.66 \pm 0.92$ & $0.57 \pm 0.89$ & 8.12 & $<.001$ \\
\hline & 25. Training to burp after milking. & $4.09 \pm 0.81$ & $3.48 \pm 1.10$ & $0.61 \pm 0.96$ & 8.01 & $<.001$ \\
\hline & Sub-total & $4.16 \pm 0.69$ & $3.57 \pm 0.86$ & $0.59 \pm 0.78$ & 9.59 & $<.001$ \\
\hline \multirow{2}{*}{$\begin{array}{l}\text { Poisoning } \\
\text { / abuse } \\
\text { (domain 5) }\end{array}$} & $\begin{array}{l}\text { 26. How to use hand sanitizer or liquid soap installed in the } \\
\text { ward. }\end{array}$ & $3.98 \pm 0.82$ & $3.70 \pm 0.97$ & $0.28 \pm 1.04$ & 3.37 & .001 \\
\hline & Sub-total & $3.98 \pm 0.82$ & $3.70 \pm 0.97$ & $0.28 \pm 1.04$ & 3.37 & .001 \\
\hline \multirow{6}{*}{$\begin{array}{r}\text { Kidnapping } \\
\text { (domain 6) }\end{array}$} & 27. Keeping the child from moving around alone in the hospital. & $4.42 \pm 0.66$ & $3.85 \pm 0.93$ & $0.57 \pm 0.99$ & 7.20 & $<.001$ \\
\hline & 28. Wearing patient uniforms at all times. & $3.71 \pm 0.87$ & $3.87 \pm 0.88$ & $-0.16 \pm 0.94$ & 2.19 & .030 \\
\hline & 29. Wearing patient bracelet at all times. & $4.19 \pm 0.78$ & $4.23 \pm 0.79$ & $-0.04 \pm 0.85$ & 0.65 & .516 \\
\hline & 30. Training child not to follow strangers. & $4.35 \pm 0.77$ & $3.81 \pm 1.02$ & $0.55 \pm 0.89$ & 7.74 & $<.001$ \\
\hline & 31. How to report strangers. & $4.19 \pm 0.80$ & $3.46 \pm 1.04$ & $0.73 \pm 0.99$ & 9.28 & $<.001$ \\
\hline & Sub-total & $4.17 \pm 0.62$ & $3.84 \pm 0.74$ & $0.33 \pm 0.64$ & 6.49 & $<.001$ \\
\hline \multirow{3}{*}{$\begin{array}{l}\text { Medical } \\
\text { devices } \\
\text { (domain 7) }\end{array}$} & 32. Precautions when using medical equipment. & $4.18 \pm 0.69$ & $3.93 \pm 0.84$ & $0.25 \pm 0.81$ & 3.82 & $<.001$ \\
\hline & $\begin{array}{l}\text { 33. How to use medical devices directly operated by caregivers } \\
\text { (parent or facility caring staff). }\end{array}$ & $4.27 \pm 0.65$ & $4.11 \pm 0.87$ & $0.16 \pm 0.90$ & 2.21 & .029 \\
\hline & Sub-total & $4.22 \pm 0.63$ & $4.02 \pm 0.80$ & $0.20 \pm 0.79$ & 3.23 & .002 \\
\hline Total & & $4.18 \pm 0.51$ & $3.72 \pm 0.58$ & $0.46 \pm 0.50$ & 11.58 & $<.001$ \\
\hline
\end{tabular}

PI=Perception of the importance; IV=Intravenous. 
4) Actual status and timing of educational methods for safety accident prevention among hospitalized children

The oral education method received a score of $4.38 \pm 0.66$ on a 5-point scale, and it was the most commonly used method of child safety education. Child safety education was most frequently performed at the time of admission, with an average score of $4.52 \pm 0.67$ (Table 4 ).

5) Nurses' Perceptions of the priority of the seven education domains by child developmental stage (ranked by item)

For children under 12 months, 55.35\%(88 participants) in- dicated that suffocation and aspiration required the most emphasis. For those aged 1 3, 4 6, and 7 12 years old, the highest score was given for falls, with response rates of 79.87\%(127 participants), $76.10 \%$ (121 participants), and $45.91 \%$ (73 participants), respectively. For ages 13-18, injury ranked highest, with $43.40 \%$ (69 participants) (Table 5).

\section{DISCUSSION}

According to the Delphi method, seven distinct domains were identified for the content of safety education. The do-

Table 4. Method and Timing of Safety Education Content for Hospitalized Children

$(N=159)$

\begin{tabular}{llc}
\hline Items & \multicolumn{1}{c}{ Contents } & M \pm SD \\
Educational method & $1: 1$ Oral education & $4.38 \pm 0.66$ \\
& Pamphlets & $3.76 \pm 1.03$ \\
& Video & $1.85 \pm 0.92$ \\
& Broadcasting & $1.96 \pm 0.94$ \\
& Photo books & $1.79 \pm 0.87$ \\
& Announcement board (bulletin) & $2.65 \pm 1.19$ \\
& Mobile application & $1.62 \pm 0.82$ \\
& Situation plays and demonstrations & $1.59 \pm 0.83$ \\
Educational timing & Group presentation and discussion & $1.72 \pm 0.99$ \\
& At the time of admission & $4.52 \pm 0.67$ \\
& Continuous education by written distribution of cautions or video & $3.16 \pm 1.04$ \\
& Whenever the caregivers changes & $3.15 \pm 0.84$ \\
& Additional education in the middle of a long-term hospitalization & $2.97 \pm 0.90$ \\
& Repetitive training in each nursing rounding & $3.42 \pm 0.74$ \\
& Education by the responsible nurse once a day & $3.06 \pm 0.86$
\end{tabular}

Table 5. The Importance of Safety Education Domains according to Hospitalized Children's Developmental Stage

$\left(N=159^{*}\right)$

\begin{tabular}{|c|c|c|c|c|c|c|c|c|c|c|c|c|c|c|c|}
\hline \multirow{3}{*}{ Domain } & \multicolumn{3}{|c|}{$<12$ months } & \multicolumn{3}{|c|}{ 1 3 years old } & \multicolumn{3}{|c|}{$4 \sim 6$ years old } & \multicolumn{3}{|c|}{ 7 12 years old } & \multicolumn{3}{|c|}{ 13 18 years old } \\
\hline & $1 \mathrm{st}$ & 2nd & $3 \mathrm{rd}$ & 1st & 2nd & $3 \mathrm{rd}$ & 1 st & 2nd & $3 r d$ & 1 st & 2nd & $3 r d$ & 1 st & 2nd & $3 r d$ \\
\hline & $\mathrm{n}(\%)$ & $\mathrm{n}(\%)$ & $\mathrm{n}(\%)$ & $\mathrm{n}(\%)$ & $\mathrm{n}(\%)$ & $\mathrm{n}(\%)$ & $\mathrm{n}(\%)$ & $\mathrm{n}(\%)$ & $\mathrm{n}(\%)$ & $\mathrm{n}(\%)$ & $\mathrm{n}(\%)$ & $\mathrm{n}(\%)$ & $\mathrm{n}(\%)$ & $\mathrm{n}(\%)$ & $\mathrm{n}(\%)$ \\
\hline \multirow[t]{2}{*}{ Falls } & 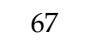 & 60 & 18 & 127 & 21 & 8 & 121 & 10 & 10 & 73 & 21 & 24 & 49 & 15 & 28 \\
\hline & $(42.14)$ & (37.74) & (11.32) & (79.87) & (13.21) & $(5.03)$ & (76.10) & (10.06) & $(6.29)$ & $(45.91)$ & (13.21) & (15.09) & $(30.82)$ & $(9.43)$ & $(17.61)$ \\
\hline \multirow[t]{2}{*}{ Injury } & 2 & 18 & 65 & 2 & 51 & 41 & 14 & 54 & 38 & 53 & 50 & 28 & 69 & $4 \varepsilon$ & 27 \\
\hline & $(1.26)$ & (11.32) & (40.88) & $(1.26)$ & (32.08) & (25.79) & (8.81) & (33.96) & $(23.90)$ & (33.33) & (31.45) & (17.61) & (43.40) & (30.19) & (16.98) \\
\hline \multirow{2}{*}{$\begin{array}{l}\text { Electric shocks/ } \\
\text { burns }\end{array}$} & 0 & 2 & 19 & 3 & 11 & 37 & $y$ & 35 & 30 & 6 & 28 & 36 & 4 & 36 & 31 \\
\hline & $(0.00)$ & (1.26) & (11.95) & $(1.89)$ & $(6.92)$ & (23.27) & $(4.40)$ & (22.01) & (18.87) & $(3.77)$ & (17.61) & $(22.64)$ & $(2.52)$ & (22.64) & (19.50) \\
\hline \multirow{2}{*}{$\begin{array}{l}\text { Suffocation/ } \\
\text { aspiration }\end{array}$} & 88 & 50 & 11 & 25 & 47 & 19 & 4 & 21 & 15 & 1 & 7 & 12 & 2 & 3 & 4 \\
\hline & (55.35) & (31.45) & $(6.92)$ & (15.72) & (29.56) & (11.95) & (2.52) & (13.21) & (9.43) & (0.63) & $(4.40)$ & (7.55) & (1.26) & (1.89) & (2.52) \\
\hline \multirow{2}{*}{$\begin{array}{l}\text { Poisoning/ } \\
\text { abuse }\end{array}$} & 1 & 17 & 27 & 2 & 18 & 33 & 9 & 16 & 26 & 8 & 17 & 15 & 4 & 3 & 7 \\
\hline & $(0.63)$ & (10.69) & (16.98) & $(1.26)$ & (11.32) & (20.75) & (5.66) & (10.06) & (16.35) & $(5.03)$ & (10.69) & $(9.43)$ & $(2.52)$ & $(1.89)$ & $(4.40)$ \\
\hline \multirow[t]{2}{*}{ Kidnapping } & 0 & 3 & 5 & 0 & 3 & 2 & 0 & 2 & 10 & 0 & 7 & 6 & 10 & 17 & 20 \\
\hline & $(0.00)$ & (1.89) & $(3.14)$ & $(0.00)$ & $(1.89)$ & $(1.26)$ & $(0.00)$ & $(1.26)$ & $(6.29)$ & $(0.00)$ & $(4.40)$ & $(3.77)$ & $(6.29)$ & (10.69) & (12.58) \\
\hline \multirow{2}{*}{$\begin{array}{l}\text { Medical } \\
\text { devices }\end{array}$} & 1 & 9 & 14 & 0 & 8 & 19 & 4 & 15 & 30 & 18 & 29 & 38 & 21 & 37 & 42 \\
\hline & $(0.63)$ & $(5.66)$ & $(8.81)$ & $(0.00)$ & $(5.03)$ & (11.95) & (2.52) & $(9.43)$ & (18.87) & (11.32) & (18.24) & $(23.90)$ & (13.21) & $(23.27)$ & (26.42) \\
\hline
\end{tabular}

*Multiple answers. 
mains derived in this study are different from existing analyses of indoor or outdoor areas where safety accidents may occur. The Child Safety Accident Survey released by the Korea Consumer Agency [2] classified safety accident areas as those where there is the possibility of "injury caused by fixed or moving objects", "falling", "tripping/sliding", "cut/stab lacerations", and so on. In Nam's study [18], daycare center safety accidents were categorized as "lacerations", "falling", "collisions with objects", and "collisions between people". The hospital environment has a variety of devices and spaces, such as wheeled beds, wheelchairs, and poles, and hospitalized children are exposed to very unfamiliar environments. Their movement is limited by the intravenous (IV) injection lines and other medical devices. For this reason, the domains to be considered for accident prevention education for hospitalized children must be more specific than those identified in previous studies. Therefore, the results of this study, which presented detailed sub-topics and classifications of the areas where hospitalized children can have safety accidents, can be considered to provide a basis for hospitalized children's safety education in the future.

Meanwhile, as suggested by previous research, the present study also identified falls as an important area in the prevention of safety accidents $[8,9,16]$. Similar findings were reported by the Korea Consumer Agency in their 2017 Child Safety Accident Trend Analysis [2]. The importance of falls is underscored by the very high fall rate of $67.8 \%$ that was documented in the Risk of Serious Injury Report [2]. Therefore, it is believed that focusing on the details of the fall domain described in this study will lead to a decrease in fall incidence.

A comparative analysis of nurses' perceptions of the importance of hospitalized children's safety education and the actual status of such education showed statistically significant differences in all seven domains $(\mathrm{t}=11.58, p<.001)$. In other words, the actual safety education provided by nurses was poorer than their perceptions of importance for all content domains of safety education. This discrepancy exists because nurses are well aware of the necessity of safety education to prevent accidents among hospitalized children, but they do not know which content to implement owing to insufficient data. As such, we consider that children and caregivers are not provided with appropriate education. Therefore, this study can be used as a basis for the development and implementation of safety education methods by providing nurses with basic data related to safety education for hospitalized children.

In our analysis of the importance of safety education content domains according to the child's developmental stage, it was found that falls and injury were important topics for children of all ages. In addition, suffocation and aspiration educa- tion was found to be more important for young children than for school-age children. However, education on medical devices was considered to be important for school-age children. This result is similar to that found in a study of age-related injury characteristics of hospitalized children undergoing emergency medical care [19]. Among younger children, falling, slipping, and foreign body aspiration were ranked high; however, as children grow older, the importance of blunt trauma increased. Therefore, it can be said that education regarding nearby medical devices is important for older children.

In the survey conducted in this study on methods of preventive education for safety accidents among hospitalized children, oral education was the most commonly-used modality, which shows that current clinical practice is limited to either oral or written methods. This demonstrates the necessity of more actively using the above-described methods to prevent safety accidents among hospitalized children. As shown in Jung's study [20], which confirmed the positive effect of education using videos and booklets on patients' understanding of hospital life and satisfaction, and Kim's study [21], which confirmed the effectiveness of mathematics education application, educational materials using visuals and concrete manipulations stimulate sight and hearing simultaneously and provides surrogate experiences to promote more accurate understanding. Thus, using more diverse teaching methods can contribute to improving the efficiency of nurses' work and increasing the effectiveness of education.

In this study, it was concluded that both the primary caregiver and the child should be included in prevention education for safety accidents at the time of admission. According to Shin, Yoo and Park's study [22], safety behavior practice is higher for individuals who have experienced of safety education. For children who spend more time with caregivers than with nurses, safety education is especially important for the caregivers. In addition, it can be expected that the efficiency of child safety accident prevention education can be enhanced by providing continuing education both during and after admission owing to the nature of child hospitalization, where caregivers frequently change.

In our investigation of additional safety accident prevention management strategies, the importance of educational management and environmental management was confirmed. In terms of educational management strategies, standardized manuals, continuous education, brief report writing, and educational material development were suggested. In the current clinical education on prevention of safety accidents among hospitalized children, guidance on falling and abduction is mainly based on Joint Commission International certification standards [11]. This reflects real-world circumstances, where there is no specific guidance on the measures to be taken in the 
event of safety accidents other than falls and abduction. Moreover, although there is a format to be followed when reporting falls, the procedure is complicated, potentially contributing to mistakes and omissions. Although prevention education should be customized according to age, there is a practical limitation in implementing safety accident prevention education because there is no data exist on interventions for the prevention of age-related safety accidents. Based on the results of the hospital environmental management strategy, it is necessary to establish a safe environment so that accidents do not occur, and it is necessary to collect the opinions of caregivers and children, as well as those of nursing providers.

Korean research on the safety education of children has mostly been conducted in elementary schools and childcare facilities, and there is a lack of research on safety accident prevention education for hospitalized children [23]. As the participants of the previous studies were also focused on falls, this poses a limitation in terms of comparing these results with those of previous studies. Therefore, further studies should investigated the full range of safety accidents among hospitalized children. In particular, educational research should be actively carried out to promote the safety of hospitalized children. Through these studies, comprehensive and systematic educational materials can be developed and implemented using various methods to enhance nurses' child safety knowledge and how they impart such education. The provision of adequate education to caregivers and children will increase the safety of hospitalized children.

\section{CONCLUSION}

The purpose of this study was to develop educational contents to enable nurses to prevent safety accidents among hospitalized children and to assess the safety education that nurses impart to hospitalized children and their caregivers. This study was conducted to provide a basis for the development of programs for practical safety education. Although education regarding the prevention of safety accidents among hospitalized children is necessary, this study confirmed that it is being imparted in a limited manner in clinical practice. The results of this study, if applied to clinical practice, can help contribute to child safety.

\section{Conflict of interest}

No existing or potential conflict of interest relevant to this article was reported.

\section{REFERENCES}

1. Korea Ministry of Health and Welfare. 2017 Child safety accident status [Internet]. Sejong: Korea Ministry of Health and Welfare; 2017 [cited 2018 December 22]. Avaliable from:

http://www.index.go.kr/potal/main/EachDtlPageDetail.do?idx _cd=2711.

2. Korea Consumer Agency. 2017 Child Safety Accident Trend Analysis [Internet]. Chungcheongbuk-do: Korea Consumer Agency; 2018 [cited 2018 December 22]. Avaliable from:

http://www.cpb.or.kr/brd/m_46/view.do?seq=2191\&srchFr=\& $\operatorname{srchTo}=\& \operatorname{srchWord}=\& \operatorname{srchT} p=\& \mathrm{itm} \_s e q \_1=0 \& \mathrm{itm} \_$seq_2=0\&mu 1ti_itm_seq=0\&company_cd=\&company_nm=\&page $=1$.

3. Korea Consumer Agency. Case analysis of child safety accidents. Chungcheongbuk-do: Korea Consumer Agency; 2014 [cited 2016 December 1]. Avaliable from:

https://www.kca.go.kr/brd/m_367/down.do?brd_id=G026\&se $\mathrm{q}=432 \&$ data $\_$t $p=$ A\&file_seq $=1$.

4. Korea Consumer Injury Surveillance System. Child safety accident trend analysis. Chungcheongbuk-do: Korea Consumer Agency; 2016 [cited 2016 December 1]. Avaliable from:

https://www.ciss.go.kr/www/selectBbsNttView.do?key=187\& bbsNo=84\&nttNo=15898\&searchCtgry=\&searchCnd=all\&search Krwd=\&pageIndex=1\&pageUnit=10\&integrDeptCode $=$.

5. Korea Consumer Agency Dispute Resolution Team 2. Survey on healthcare disputes related to hospital safety management. Survey Roport. Chungcheongbuk-do: Korea Consumer Agency; 2006. Report No.: GOVP1200722863.

6. Park EP, Oh WO, Kim MR. Factors affecting nursing students' perception on pediatric patient safety culture and nursing activity. Child Health Nursing Research. 2017;(23)4:534-542. https://doi.org/10.4094/chnr.2017.23.4.534

7. World Health Organization. Conceptual framework for the international classification for patient safety version 1.1 [Internet]. Geneva: World Health Organization; 2009 [cited 2018 December 22]. Avaliable from:

https://www.who.int/patientsafety/taxonomy/icps_full_report.pdf.

8. Park SY, Ju HO. The effect of pediatric inpatient fall prevention education on caregivers' fall-related knowledge and preventive behaviors. The Journal of Korean Academic Society of Nursing Education. 2017;(23)4:398-408.

https://doi.org/10.5977/jkasne.2017.23.4.398

9. Shin HJ, Kim YN, Kim JH, Son IS, Bang KS. A pediatric fall-risk assessment tool for hospitalized children. Child Health Nursing Research. 2014;20(3):215-224.

https://doi.org/10.4094/chnr.2014.20.3.215

10. Cooper CL, Nolt JD. Development of an evidence-based pediatric fall prevention program. Journal of Nursing Care Quality. 2007; 22(2):107-112.

https://doi.org/10.1097/01.NCQ.0000263098.83439.8c 
11. Razmus I, Wilson D, Smith R, Newman E. Falls in hospitalized children. Pediatric Nursing. 2006;32(6):568-572.

12. Neiman J, Rannie M, Thrasher J, Terry K. Kahn MG. Development, implementation, and evaluation of a comprehensive fall risk program. Journal for Specialists in Pediatric Nursing. 2011;16(2):130139. https://doi.org/10.1111/j.1744-6155.2011.00277.x

13. Hill-Rodriguez D, Messmer PR, Williams PD, Zeller RA, Williams AR, Wood M, et al. The Humpty Dumpty Falls Scale: A case-control study. Journal for Specialists in Pediatric Nursing. 2009;14(1): 22-32. https://doi.org/10.1111/j.1744-6155.2008.00166.x

14. Gielen AC, McKenzie LB, McDonald EM, Shields WC, Wang MC, Cheng YJ, et al. Using a computer kiosk to promote child safety: Results of a randomized, controlled trial in an urban pediatric emergency department. Pediatrics. 2007;120(2):330-339. https://doi.org/10.1542/peds.2006-2703

15. Carayon P, Schoofs Hundt A, Karsh BT, Gurses AP, Alvarado CJ, Smith M, et al. Work system design for patient safety: The SEIPS model. Quality and Safety in Health Care. 2006;15(1):50-58. https://doi.org/10.1136/qshc.2005.015842

16. Sung YH, Gwun IK, Kim KH. Factors influencing falls in inpatients. Journal of Korean Academy of Fundamentals of Nursing.
2006;13(2):200-207.

17. Krippendorff KH. Content analysis: An Introduction to its methodology. 4th ed. Pennsylvania: SAGE publications; 2018. p. 1-472.

18. Nam YJ. The types of age-specific safety accident in childcare center and content analysis [master's thesis]. Seoul: Jungang University; 2013. p. 1-183.

19. Ahn KA, Kim ES, Lim KS. Age-related injury profile in childhood. Journal of Trauma and Injury. 2009;22(1):87-96.

20. Jung HC. The effect of in-patient guide movie and booklet programs on understanding of hospital life and satisfaction with the programs. Journal of Korean Academy of Nursing Administration. 2008;14(1):45-50.

21. Kim B. Development and application of mobile-based math learning application. Journal of Korea Society Educational Studies in Mathemathics School Mathemathics. 2017;19(3):593-615.

22. Shin HS, Yoo IY, Park HY. Safety perception and behaviors of mothers with school age children. Journal of East-West Nursing Research. 2007;13(2):130-137.

23. Han J. Nurses' management of safety accidents for hospitalized children: A structural equation model [master's thesis]. Seoul: Korea University; 2018. p. 1-101. 